\title{
Economic Coordination Contracts and their Role in Integration of Farmers Markets
}

\author{
MSc. Eglantina Pazaj \\ Ph.D. Candidate Faculty of Economics and Agribusiness, Agricultural University of Tirana \\ E-mail: epazaj@ubt.edu.al \\ Prof. Dr. Alba Dumi \\ Management Department" University of Vlore, Albania \\ Dean of Graduated School "Ismail Qemali" University of Vlore \\ E-mail: alba.besi12@gmail.com
}

\section{Doi:10.5901/ajis.2015.v4n1p435}

\section{Abstract}

The basic goal is to provide a theoretical background not only for analysis of specific contracts in agriculture that should operate between producers (agents) and processors (Principal). This theory deals with situations in which an economic entity, in case the total processing industry, but not limited to, (the principal) of" delegate" responsibilities (tasks) an agricultural producer of raw materials (the agent).Delegation of tasks that the agent makes decisions that affect not only their activity but also nit's own principal. Normally, in a principal-agent relationship, the latter is threatened by for formal contracts that represent the interests of the principal in exchange for a fee. The purpose of this paper is to examine the relationship between actors in the system agro-business. Thus, we have under study for years olive Phil ere for the coming years 2012, 2013 2014. One of the key elements that we studied is agricultural contracts. 1. What is the role of agricultural contracts in agro-business system? 2. Do agricultural contracts affect in sustainability between all stakeholders in the system? 3. Are these contracts practiced in our country? 4. What is the role of government in promoting linkages and mutual impacts in the system? To get an answer on questions above and others we have used a questionnaire and we interviewed 60 farmers who grow and produce olives, and 60 agro-processers that produce olive oil.

Keywords: Agricultural products, International cooperatives, Environment, Olive oil, Contracts.

\section{Introduction}

In this paper research we are, interested in exploring possible roles of farmers' cooperatives in dealing with the fundamental problems of coordinating economic activity in the real world of uncertainty. The study and evaluation of the results so far and Interdependencies reciprocal relationships between all the links in the agro-business system are almost non-existent. This is because of actors including every link of the system that are not coordinated between them which makes the system having a low performance.

Non-coordination of the actors with each other makes the system links AGB to be separated from each -other. There is an absence of mutual benefit and mutual influences in system. Depending on such conditions will be difficult the adaptation of supportive policies for all system stakeholders. In both cases, the transactions involve exchanges of claims to benefits and agreements- implicit and explicit contracts. In transactions across markets, explicit prices are central to coordination and contracts tend to be more specific.

\subsection{Relationship between Processors and Agents (Producers)}

In a principal - The agent relationship is threatened by formal or informal contracts, which represent the interests of the principal in exchange for a fee. Their relations are characterized by the following features like this: 1 . Functions of the weakness of the principal and the agent does not match. The level of benefits and costs of the agent is influenced by two factors of productivity: First, the level of compensation that increases his personal wealth the secondly, the efforts to be undertaken to realize the obligations to third parties. - The principal and agent have different attitudes towards risk and actions against the principal and the agent will be diverse, it is assumed that principal is risk neutral and opposed to his 
agent. The information between the principal and the agent area symmetrical distributed.

The hypotheses raised are:

1. There is a strong relationship between the links of AGB system.

2. Contracts are critical for creating and strengthening linkages between actors in the system.

The interviews that were conducted were occasional. They include mainly farmers and agro- processers in south of Albania area but also from middle regional Albania. The first part of the questionnaire includes identifying information, the second part includes economic information while the third part includes the information about the identifying problems that exist between farmers and agro-processors and evaluation of actors for agricultural contracts. The situation in which Albanian agro-business system is given in the scheme below: See scheme 1,

Our country is a developing country and as such is characterized by fragmentation and even small farms where most farms produce just as home consumption. As far as the production is low these farmers find it difficult to operate in the market and to cope with market competition. In our country markets suffer lack of a good consolidation and as such it cannot guarantee the sale of production of one hand and the risk is very high on the other hand.

The results of the study show that: no matter the collection costs information is symmetric or not, manufacturer rents inventory facility for chain members' interests is better than the recycler does when a chain member is responsible for rental facility costs alone. No matter the collection costs information is symmetric or not, using the coordination of the rebate and penalty contract can avoid the profit loss of the reverse double marginalization. No matter the collection costs information which recycler passes to manufacturer is true or not, the recycler's expected profit will not less than his reserved profit in symmetric information and decentralized decision making structure at least.

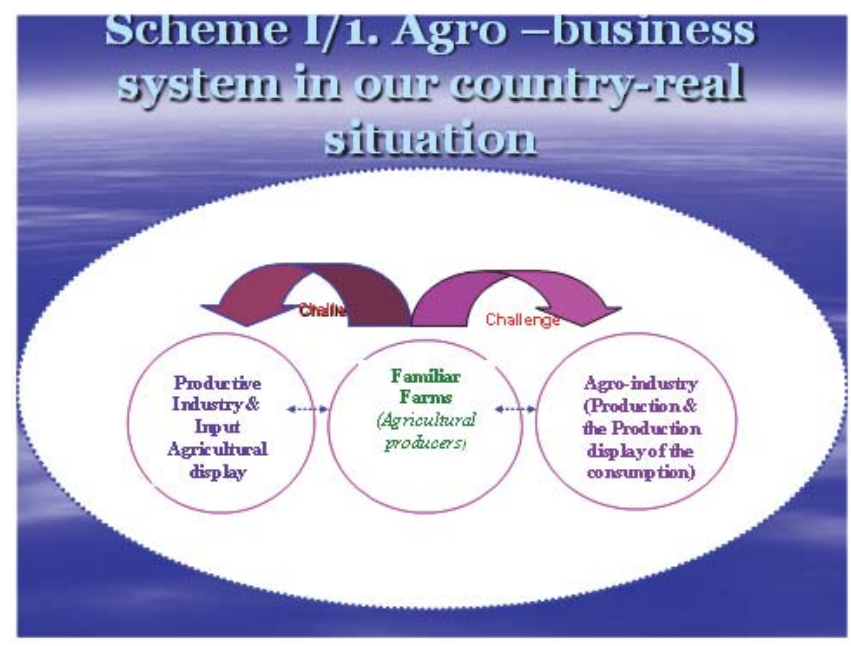

Source: Albania and Agricultural display,

The end result of activity does not only depend on the efforts of the agent, but also by other factors so the principal cannot directly assess the efforts of the agent on the basis of the final result. In the agro-food sector, the problems between the principal and the agents are subject to the requirements relating to the supply of high quality inputs. However, when it is costly to monitor quality, full integration within the firm is just one of the options in the available selection. The failures selection, the presence of moral risk, requires no doubt, the existence of providers with good will, as well as sufficient information about quality, in order to build a monitoring to risk.

\subsection{Supply chains and issues between players in supply}

In Interviews taken the majority of farmers interviewed about $80 \%$, and send their production (olive) directly to the agroprocessor although the selling price is lower than the market. In this way they try to avoid the risk of production and accepting so the lowest profit.

There excluded the cases of some farmers who tend to sell their production in the market itself.

In our country there are about 133 factories of olive processing plant but only four are considered the biggest 
factories which manage to realize a production of enough high quality.

These factories have been added more recently seeing olive oil as a product which can be of great benefit as it has high nutritional value and this resulted in an increase of market demand for the consumption of this product.

Some of the products that these factories realize are:

1. Olive oil for use of the farmer,

2. Olive oil "extra virgin"

3. Oil "virgin"

4. Olive "grain, salted, stuffed"

5. Olive " salted grain "

6. Oil "organic extra virgin".

Most of these processing plants are built near the areas in which the olives are cultivated. Most of these factories offer their technology to serve farmers with a specified fee. So, farmers the realized productions they elaborate on these factories upon fixed payment and then sell the product (olive oil) separately in the market.

But there are factories that buy the product to farmers or to collection points although these collection points in some areas do not work at all, in order proceed well on it and then selling the product for profit.

Agro supply constitutes the subject of analysis and evaluation in this article. In their operation involved a number of stakeholders. In this paper, by using game theory, principal-agent theory and operations research, reverse supply chain pricing strategies and contract coordination problems are discussed under the conditions of chain members go to rent additional facilities when they do not have enough inventory facility capacity. Technological level leaves much to be desired.

Average production capacity for factories that were taken in the analysis was 25 quintals / hour.

As far as most of these agro-processing factories resulting in small, they find it difficult to create a brand for their product, and certainly they have difficulties in providing sales market.

The latter would be conducted through bureaucratic relationships, and the former would be similar to those across markets, but with the added potential of the patrons influencing the firm's performance through an elected board. A well functioning market would require the cooperation of the three economic agents: the farmers, the government and agroprocessors (firms) through two market as that of factors and that of production. But the surveys that were conducted showed that the interaction of economic agents with one another does not function properly. As farmers and agroprocessors also require a greater support from the government in order to sell their products and increase revenue. Factories work during October-February period which coincides with the olive harvest. Some factories produced themselves a piece of raw materials while the rest is acquired from farmers or wholesale from collection points.

However, regarding the question of whether was ever signed a sales contract between farmers and agroprocessors, they responded negatively. There was no contract of sale between farmers and agro-processors written in legal conformity. Usually farmers and agro-processors agree with each other through "oral contracts", that they were loyal to each other for the quantity of production, quality and sometimes the sale price. Through oral agreement the parties agree on the amount of production, sales price and quality of production.

But this agreement often could be broken as market conditions change.

Farmers intended to sell their product at a price much higher in order to maximize their profits. On the other hand agro-processors intended purchase raw materials at a price as reasonable in order to minimize production costs and increase profits.

An important question is the potential advantages of cooperatives organization compared with coordination strictly across the markets. But reciprocal links and Interdependencies between actors and links in the system are almost nonexistent.

In the chart above, note that the well-functioning of a certain supply, could not be carried further bilateral relations and effects between producers and suppliers of agricultural inputs and agricultural producers, between the latter and the processing industry between her and distributions processed products and lastly, between distributors of products and consumers. Therefore, we will focus on the second link of the chain and just in relationships, agro- processing industry manufacturer. ( Bogetoft S, Henrik 2004) 


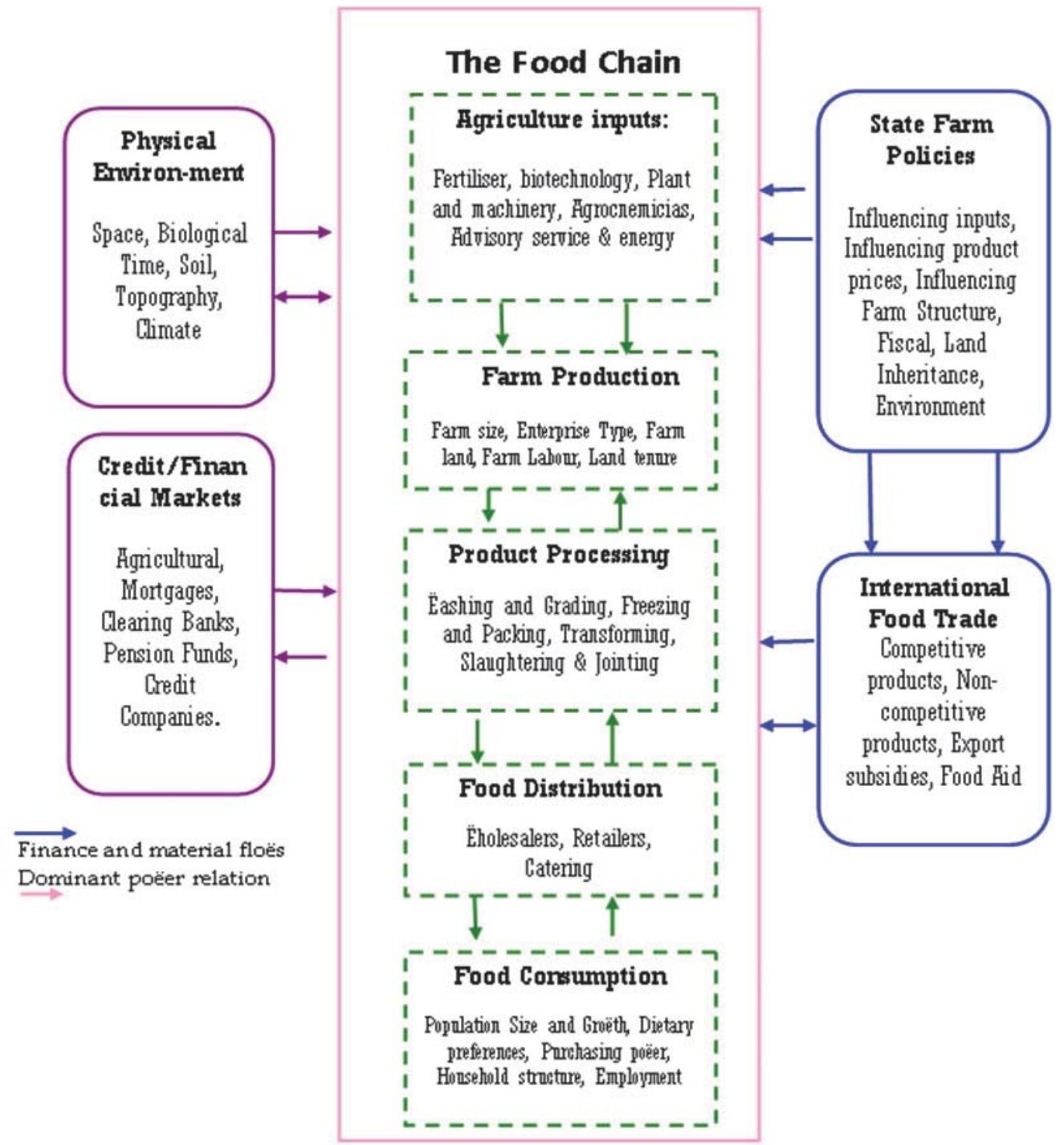

Scheme 1: Supply chains in the food chain

\subsection{Contractions relationship and system issues regarding with it}

\subsubsection{Contractual relationship - rationality and opportunism}

The theory of contracts is based on two important concepts, the assumption of reasoning, (rationality) and the assumption of opportunism. The based concept of the assumption of reasoning (rationality) means that individuals, based on the information that they possess, are interested to choose the best ways to achieve their goals .Referring to a concept of " rationality restrictive ", it should be noted that an individual cannot predict all economic situations or state of nature, therefore, must accept the concept of incomplete contracts, therefore renegotiation is necessary .

It should be emphasized that all agro-processors use, it was raw material in $100 \%$ of the country and nobody was buying the raw material from imports, without ensuring that all the production needed by country (domestic) production. From an assessment made in connection with the issue of supply with raw materials from country (domestic) production resulted: 


\begin{tabular}{|c|l|c|c|c|c|c|}
\hline $\mathrm{Nr}$ & Problems / Evaluation & Quantity of prob. & Average prob. & Little prob & More or less prob & No prob \\
\hline I & Problems related to: / Evaluation & 1 & 2 & 3 & 4 & 5 \\
\hline 1 & H1. Number of resources to supply raw materials & & & & & \\
\hline 2 & H2. Diversification of supply sources & & & + & & + \\
\hline 3 & H3. The sustainability of a supply sources & & & + & & \\
\hline 4 & H4. Reliability of supply sources & & & & & + \\
\hline 5 & H5. The quantity supplied & & & & & \\
\hline 6 & H6. The sorts of supply & & & + & & \\
\hline 7 & H7. Quality of supply & & + & & & \\
\hline 8 & H8. Time of supply & & & & & \\
\hline 9 & H9. Cost of supplies & & & & & + \\
\hline 10 & H10. Standards supply & & + & & & + \\
\hline 11 & H11. Supply inventory costs & & & & + \\
\hline 12 & H12. Opportunistic behavior of suppliers & & & & & + \\
\hline 13 & H13. The risk of supply & & & & & + \\
\hline 14 & H14. The rate of supply & & & + & & + \\
\hline
\end{tabular}

The table above gives an average estimate for the 60 agro-processors surveyed.

While the average assessment that resulted from the survey of 60 agro-processors for the problems encountered in connection with the application of contracts for the interior (domestic) supply results:

a) This means that an individual will sign a contract only if it is profitable to .Advantages of the assumption of rationality and opportunism is: 1 . these assumptions are effective descriptive. b) Secondly, we may want to put (impose) a rational and opportunistic behavior, as part of the solution that we seek. c) Thirdly, the assumption of rationality and opportunism puts theory of contracts as an integral part of modern neoclassical microeconomics.

\begin{tabular}{|c|l|c|c|c|c|c|}
\hline $\mathrm{Nr}$ & Problems / Evaluation & $\begin{array}{c}\text { Quantity of } \\
\text { prob. }\end{array}$ & $\begin{array}{c}\text { Average } \\
\text { prob. }\end{array}$ & Little prob & $\begin{array}{c}\text { More or } \\
\text { less prob }\end{array}$ & No prob \\
\hline I & Problems related to: / Evaluation & $\mathbf{1}$ & $\mathbf{2}$ & $\mathbf{3}$ & $\mathbf{4}$ & $\mathbf{5}$ \\
\hline 1 & H15. The possibility of making assignments contracts & + & & & & \\
\hline 2 & H16. Possibility of carrying out assignments contracts & + & & & & \\
\hline 3 & H17. Availability of reliable parts & & & & + & \\
\hline 4 & H18. The possibility of providing a good price & & + & & & \\
\hline 5 & H19. Reliability of partners & & + & & \\
\hline 6 & H20. The presence of a limited offer \& fragment. & & & & \\
\hline 7 & H21. Reliability to arbitration bodies & & & + & \\
\hline 8 & H22. Enforcement of contracts terms of quantity & + & & & \\
\hline 9 & H23. Enforcement of contracts terms of quality & + & & & \\
\hline 10 & H24. Enforcement of contracts regarding the supply time & & & & \\
\hline 11 & H25. Enforcement of contracts for terms of supply continuity & + & & & & \\
\hline 12 & H26. The risk of supply & & + & & \\
\hline
\end{tabular}

The table above gives an average estimate for the 60 agro-processors surveyed.

In the table above is given a comprehensive assessment regarding to the application of contracts.

Some of the reasons that affect agricultural mal-functioning contracts were:

1. The lack of information for farmers on compelling and implementing of agricultural contracts

2. Being the agro-processors factories were built near areas where cultivated, the olive were not seen as a necessity on applying an farming written contract

3. The parties in most of the areas where they conducted survey, were loyal to each other through oral agreement previously performed.

4. Another reason to avoid the application of a farming written contract was to avoid exposure to the sale price for the parties.

5. Another reason not implementing the contracts was the avoidance of notary fees and taxes.

Only 4 agro-processor factories which have a high production capacity not only manage to produce more quality olive oil extra virgin but have failed to export this product in countries such as Switzerland, Germany, and America etc. 


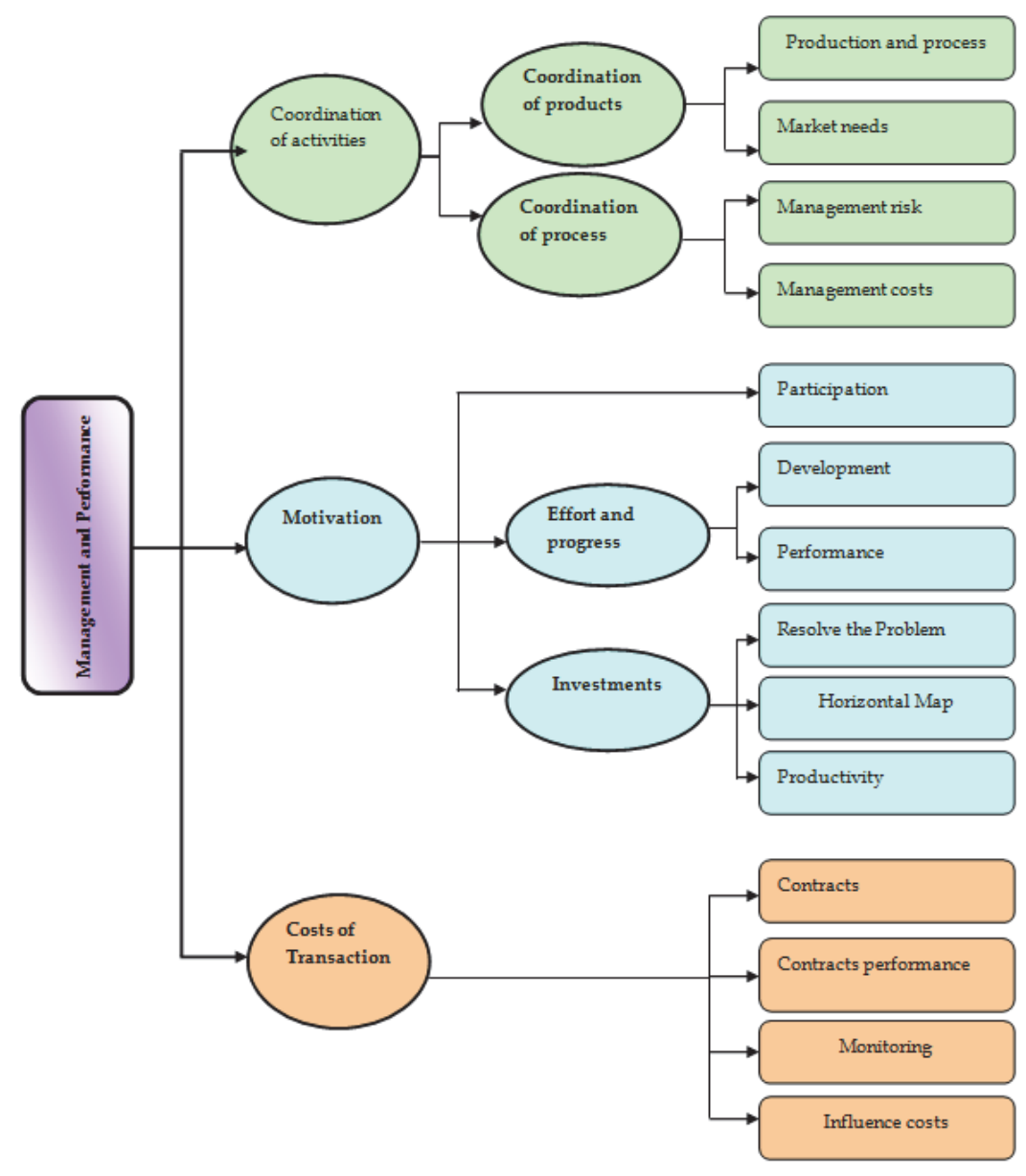

Scheme 2. Hierarchy of goals for contract design

\subsection{Coordination of production and planning hierarchical}

There are two basic approaches to the coordination of production

- A planning approach is hierarchical, with a central decision-making determines the actions of any manufacturer and coordinates the behavior through instruction. (Bogetoft, Henrik 2004)

- In formal literature has two important ways of explaining the behavior. (Axelrod, Robert. 1981)

- One of these areas is the so-called game theory (team). A team is a group of people who agree on behalf of a general purpose, with the objective of who cooperates solves a common problem, through actions and private information from any member. (Holmstrom B. 1997)

Another line of explanation is planning procedures and multilevel iterative. The subject of this approach remains the problem of coordination within a divisional firm. Often contracts simultaneously use both of these coordination mechanisms. According to this logic, specific aspects are controlled by the price mechanism, while others are controlled by central decisions. Generally, overall production levels, often delegated to individual producers and coordinated by a price signals demand conditions. (Rhodes A, V. James 1981)

To determine a well-coordinated production schedule, the need of possessing the necessary information, considering here as information on income and the cost of info processors contracts, as well as information on processors. The problems become even more acute, as actors will be reveal with their private information.

For example:

- Processors cannot find it profitable to reveal profit for the product, as long shows what can be shared with manufacturers.

- Similarly, manufacturers may be reluctant to reveal the true costs of production, because it can improve their 
position in a bargaining relationship with the processors.

Thus, considering the above, it should be noted that coordination hierarchical production requires incentive schemes to motivate real detection information of a decision maker.

\subsection{Analysis and evaluation of goals of contracts}

In favor of the analysis and evaluation of functioning of the system of contracts, we propose to use a certain hierarchy of goals. The management gradually being focus for enterprises. Enterprise in supply chain is independent. The entity and they all have their own target and strategy. The purpose of the joining in supply chain is for their respective interest. However targets and strategies between medical enterprises in supply chain and supply chain Management are in coordination.

These cause that the supply chain management final target failed. So we will set some constraint for supply chain, which cause supply chain interest raised. Supply chain contracts will solve the problem well, meanwhile within the proper contract parameter; the interest of enterprises in supply chain will be no less than the interest without contracts.

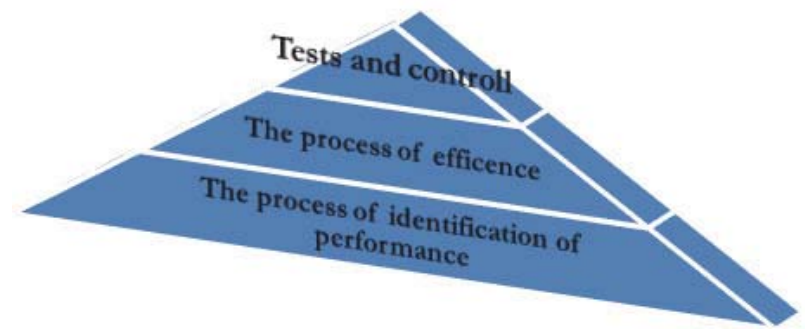

Source: Callon A, JERM USA, 2009, the identification of administrative framework for the market

\section{Results of the Survey}

The motivation for signing a contract depends on the preferences of the parties. From the economic stand-point, the main purpose of a contract is integrated profit maximization. In terms of a satisfactory profit level, anyone can become better and making sure that it is possible to redistribute profits, without adversely affecting the behavior of the contracting parties. (Axelrod, Robert. 1981)

Contracts resulting in maximum integration profits, considered as the first good of efficient contracts.

The main objectives of contracts.

Each contract must serve two main purposes:

- First, a contract should coordinate production in order to ensure that the appropriate manufacturers are producing the right amount of appropriate products in a timely and appropriate way.

- Second, the contract should motivate the parties, giving private interests in making decisions that maximize profit coordinating integrated. (Galbraith, J. K. 1967)

- Thirdly, it can reduce costs. A common potential conflict between coordination and motivation is largely due to the dual role of prices, but on the other hand it should be noted that prices send signals coordination and affect the distribution of benefits from contracts. It should be emphasized that transaction costs can be defined in a narrow sense or wide.

In the strictest sense possible, the term refers to transaction costs connectivity costs, monitoring and enforcement of contracts. (Rhodes A, V. James 1981)

On the other hand, seen in a broader perspective, transaction costs consider any kind of barrier that hinders efficient decentralized exchanges. Considering the above, we must emphasize that the costs of production and transaction costs are indicated and allocated. This is a common assumption in the theory of transaction costs.

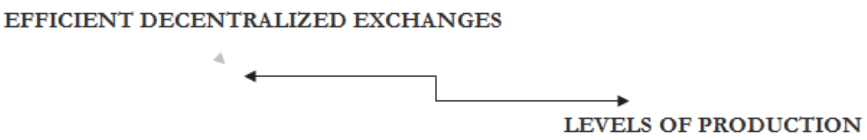


A well-known problem of coordination has to do with the choice of production levels at different stages of the supply chain. If different stages operate individually and independently choose their levels of production, to maximize their profits, may double marginalization problem. Each stage of the production chain uses its market power by reducing the amount that is supplied in order to increase the price. This will cause a double drop in supply, which in turn will reduce profit integrated. The dual problem of marginalization caused by the fact that the processor does not optimize the amount based on the production costs of manufacturers, but based on the price that he pays producers. (Holmstrom B. 1997)

If manufacturers possess market power, these prices will be above production costs. The standard remedy the problem would be a contract in two parts, one that provides a transfer price equal to marginal cost of production and another that provides an additional fixed transfer.

\subsection{The importance of the research paper}

It's the opportunity to remind how the processing enterprises, as well as the vendors themselves, can improve their business using contracts. They can reduce operating costs, ensure the required quantities of products, quality, supply deadlines etc. They can provide various equipment and supplies in quantities and at favorable prices, because the image and credibility generated from contracts with producers. (Rhodes A, V. James 1981)

Contracts enable stakeholders involved in the project to better combine resources in order to reduce the costs of activities. Using contracts, processing enterprises can reduce insurance costs, collection and distribution of products. They also can perform processing products and other activities with minimal cost, following the volume of their activity. If the company does not know the volume of activity, then it should work to ensure flexibility in its operations, to minimize the risk, as shown in the graph below:

\subsubsection{Decision making in terms of the use of contracts}

Referring $A C 1$ cost curve shows that the lowest cost is in the curve $C D$ and that represents a certain amount of production which did not know and this is a major problem in the absence of contracts. If the known quantity of production, the cooperatives can achieve a lower cost, say at point $\mathrm{E}$ to a known production volume. But if the volumes change, say from A to B, then the average costs would be higher on AC2 than the AC1. (Galbraith, J. K. 1967)

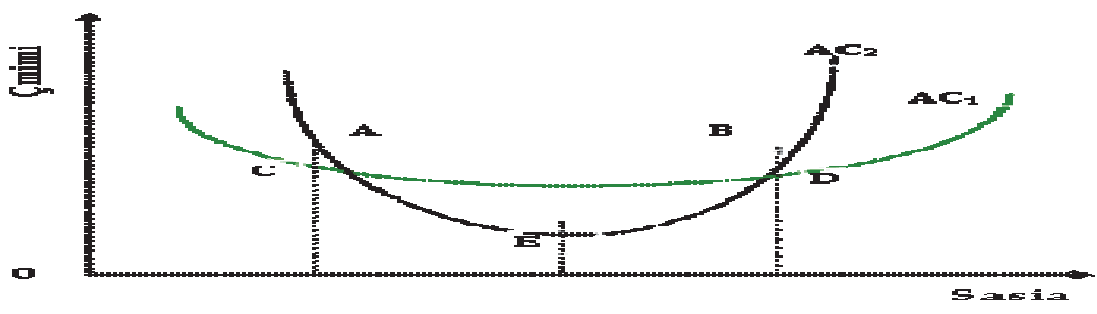

\subsubsection{Contracts have legal power to take both for producers and seller.}

They hamper foreign intervention, because guarantee that the other party will be penalized for any damages that may occur from a breach of contract. This is because they reflect the common rights and obligations of the cooperative and its members. In determining the supply is very important to consider how it affects competition in the market. In some cases, a great offer will trigger an aggressive response to competitors. In other cases, a great offer can empower competitors out of the market or prevent new competitors to enter the market. (Axelrod, Robert. 1981)

\section{Methodology of the Research}

In the empirical part of the paper, we analyses selected indicators for responsiveness of the public administration in selected Albanian programs, compared European Union (EU).

The fact that a cooperative is a superior method of coordinating economic activity in terms of transactions costs, etc., does not necessarily lead to the establishment of a cooperative. (Axelrod, Robert. 1981) This does not address the question of comparative transaction costs in establishing these alternatives, which may be substantial and deserving of empirical investigation. (Rhodes A, V. James 1981) 


\subsection{Risk allocation}

Risk allocation is an important issue in the design of contracts.

Often assumed (but it is true) that large firms are less adversarial risk than farmers. There are a number of reasons that support this conclusion. Owners of large firms find it easier to diversify their investments in the securities market (stock exchange). In contrast, manufacturers often have a high debt ratio and consequently, few opportunities for diversification of investments. (Axelrod, Robert. 1981)

Recognizing that producers are risk -averse, and the processor is neutral, it makes us appreciate that the processor must take all the risks and the manufacturer must accept payments constant.

However, it should be noted that this will generate motivation problems, which means that a manufacturer who receives a constant charge can reduce his efforts without reason, therefore, a constant charge does not provide incentives attempts. For this reason, risk -sharing arrangements should take into account the conflict between efficient risk sharing and motivation. (Coase, R. H 1937)

It is not necessary to manufacturers impose different types of risks in order to assure proper motivation. It should be emphasized that agricultural production is subject to various sources of risk. (Axelrod, Robert. 1981)

- Often, the producers affected by overall risk, for example, weather conditions.

- Agricultural production is subject to price risk from price variations and outputs.

- Product -specific risk, for example the risk that cannot be described in general terms of production provides indirect information about the efforts of manufacturers.

\section{Conclusions}

Contract design can affect the level of risk in many ways: If the contract does not allow the adjustment related to changes in production and market conditions, total risk - processor manufacturer relationship can grow. Self contracts (It is about long-term contracts and fixed prices of product to use) can generate risk.

While the average assessment that resulted from the survey of 60 agro-processors for the problems encountered in connection with the application of contracts for the interior (domestic) supply results:

These sign sales contracts in countries where export and also have succeeded in gaining even different prices in terms of product quality they produce.

Signing the contracts by agro-processors with farmers was of no problem but farmers are those who fear the signing of a contract because they are afraid not only the exposure to price but also to the quality product that agroprocessors require. From the analysis of the surveys conducted in the field and use of a multi-factorial model shows that the first hypothesis we have raised fell down as the connections between actors in the system are very weak while the second hypothesis regarding farming contracts remains as true. Once contracts play a critical role in strengthening the relationship between the actors in the system by providing elements of the solution between the parties, increasing profits, reducing costs of operation, guarantee the quantities, the quality and time of supply.

The role of government in regulating the relations between actors in the system must be the greatest. It should develop strategies that contribute to the growth and interdependencies between all the actors in the system where one of the strategies that we recommend is the contracting system functioning in agriculture. Transactions among employees or units within a firm are difficult to distinguish from relational or even neoclassical contracting. All matter what a producer is his risk of total and it currently can grow without affecting income, while allowing cost components vary.

One way to solve this problem is to avoid long-term contracts. However, this may cause uncertainty in behavior. Another possible solution is to agree that producer prices would follow a certain price index. Another way to minimize the total risk is the risk distribution under the effects of bankruptcy. Another problem is asymmetric information in the negotiation process. Asymmetric information can lead to a result of negotiation (bargaining) not efficient. Consequently, the establishment of a large part of the risk on producers can reduce the total risk in the production chain.

\section{References}

Agricultural Economics Association. Tampa, 31 July - 2 August.

Axelrod, Robert. The Evolution of Cooperation. New York: Basic 'Books, 1981.

Bogetoft, Henrik Ballebye Olsen, "Design of Production Contracts", 2004

Dumi A, Jerm "Decentralization and economy development, 2011

Dumi A, GARJMBS "Albania economy and EU standads, March 2014 
Zejneli, Dumi, Qarri,Demo, Decentralization reforms in Albania, Social Proccedia Behavior Science 2012

Heinrich Hockman, JurgenWandel, WladimirShaikin "Integratied structures in the agro-food sector, 2002

Holmstrom B., "Moral Hazard and Observability", The Bell Jurnall of Economics, 1979

Williamson O., "The Nature of the firm. Cambridge: Cambridge University Press, 1997.

Moss, C. B. and A. Schmitz. 2000. Vertical integration and trade policy: the case of sugar. Annual Meeting of the American 